\title{
The association of the amniotic fluid index (AFI) with perinatal fetal and maternal outcomes in pregnancies complicated by preterm premature rupture of membranes (PPROM)
}

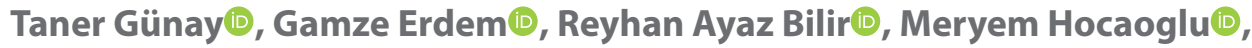 \\ Ozkan Ozdamar(D), Abdulkadir Turgut(1)
}

Medeniyet University Göztepe Training and Research Hospital, Eğitim mah. Dr. Erkin cad. Kadıköy, İstanbul, Turkey

\begin{abstract}
Objectives: To investigate association of amniotic fluid index (AFI) with perinatal fetal and maternal outcomes in pregnancies complicated by preterm premature rupture of membranes (PPROM)

Material and methods: A total of 70 singleton pregnancies complicated by PPROM at 23-33 weeks' gestation were enrolled in this prospective observational study. Data on maternal clinical and obstetric characteristics [maternal age, gravidity, parity, PPROM time, and AFI (cm), latency period, treatments, type of delivery, length of hospital stay (LOS, day)], fetal characteristics (gestational age at delivery, birth weight (g), gender) and maternal and fetal complications were recorded and compared in $A F I<5 \mathrm{~cm}(n=27)$ and $A F I \geq 5 \mathrm{~cm}(n=21)$ groups.

Results: Overall AFI was $\leq 5 \mathrm{~cm}$ in 27 (56.3\%) patients and $>5 \mathrm{~cm}$ in 21 (43.7\%) patients. No significant difference was noted in maternal clinical and obstetric characteristics, gestational age at delivery and gender of the newborn as well as in maternal and fetal complications rates with respect to AFI groups. AFI was correlated positively with latency period $(r=0.399, p=0.018)$ and negatively with postpartum LOS $(r=-0.314, p=0.030)$.

Conclusions: In conclusion, our findings seems to indicate increased likelihood of shorter latency to delivery and longer postpartum LOS with decrease in AFI after PPROM between 23-33 weeks' gestation, whereas no impact of AFI on mode of delivery and fetal or maternal complications.
\end{abstract}

Key words: Preterm premature rupture of membranes; amniotic fluid index; fetal outcomes; maternal outcomes

Ginekologia Polska 2020; 91, 8: 465-472

\section{INTRODUCTION}

Premature rupture of fetal membranes (PROM), the leakage of amniotic fluid prior to labour irrespective of gestational age, occurs in 2-25\% of all pregnancies, while PROM before 37 weeks of gestation occurs in nearly $3 \%$ of all pregnancies and referred to as preterm PROM (PPROM) [1-4].

Early recognition and appropriate treatment of PPROM is crucial for preventing potential adverse perinatal outcomes related to prematurity (i.e. neonatal morbidity and mortality) and for minimizing the risk of fetal and maternal complications [3-6]. However, PPROM continues to be a challenging condition in current obstetric practice in terms of controversies regarding the optimal timing and route of delivery to minimize maternal and perinatal morbidity $[3,5]$.
Amniotic fluid index (AFI), a widely used method for evaluation of fetal well-being, is considered a useful parameter in this regard, given its potential in predicting adverse outcomes, aiding to decide on optimal mode of delivery in pregnancies complicated by $\operatorname{PPROM}[5,7,8]$. Accordingly, presence of oligohydramnios (AFI $<5 \mathrm{~cm}$ ) after PPROM has been suggested to be associated with increased likelihood of adverse fetal (i.e. intrauterine growth restriction, fetal distress, pulmonary hypoplasia, respiratory distress syndrome, neonatal sepsis, necrotizing enterocolitis, intraventricular hemorrhage, and bronchopulmonary dysplasia) and maternal (i.e. chorioamnionitis) perinatal outcomes, contributing to an increase in neonatal sepsis and mortality [5, 8-12]. 
However, the utility of AFI after PPROM in terms of adverse perinatal outcomes has not been extensively studied along with considerable controversy among the published studies [5, 8, 9, 12-16].

This study was therefore was designed to investigate the potential association of AFI with fetal/maternal perinatal adverse outcomes in pregnancies complicated by PPROM.

\section{MATERIALS AND METHODS}

\section{Study population}

A total of 70 singleton pregnancies complicated by PPROM at 23-33 weeks' gestation were enrolled in this prospective observational study conducted at a single tertiary care center between September 2018 and September 2019. Women with singleton, non-anomalous fetuses with suspected diagnosis of PPROM at 23-33 weeks' gestation and amniotic fluid volume assessment at the time of presentation were included in the study. Presence of multiple pregnancy, cerclage major congenital anomaly, oligohydramnios, polyhydramnios, pregnancy-related hypertensive disorder, cervical dilatation $\geq 6 \mathrm{~cm}$ on admission and delivery within 2 hours of membrane rupture were the exclusion criteria of the study. Accordingly, final study population subjected to analysis was composed of 48 pregnant women due to exclusion of 22 women due to lack of PPROM diagnosis ( $n=13$ ), multiple pregnancy $(n=2)$, cervical dilatation $\geq 6 \mathrm{~cm}(n=2)$, hypertensive disease $(n=1)$, cerclage $(n=1)$, lumbar meningomyelocele $(n=1)$, idiopathic polyhydramnios $(n=1)$ and discharge at her own request $(n=1)$ (Fig. 1$)$.

Written informed consent was obtained from each subject following a detailed explanation of the objectives and protocol of the study which was conducted in accordance with the ethical principles stated in the "Declaration of Helsinki" and approved by the institutional ethics committee.

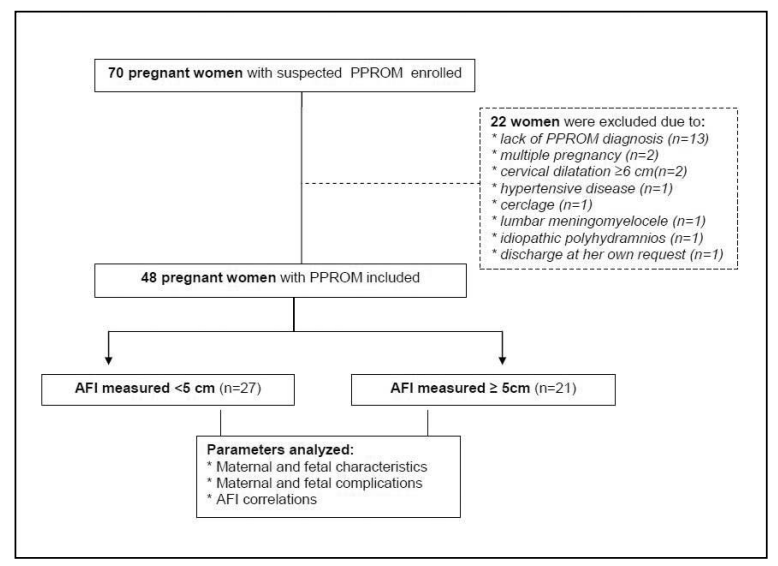

Figure 1. Study flow chart

\section{Assessments}

Data on maternal clinical and obstetric characteristics [maternal age, gravidity, parity, body mass index prior to pregnancy $\left(\mathrm{kg} / \mathrm{m}^{2}\right)$, smoking status, PPROM time, amniotic fluid appearance and AFI (cm), latency period (days from rupture of amniotic sac to the delivery), treatments (steroid, magnesium), type of delivery, length of hospital stay (LOS, day)], fetal characteristics (gestational age at delivery, birth weight (g), gender) and maternal complications (placental abruption, retention, endometritis, bleeding, chorioamnionitis, last CRP before delivery, WBC and body temperature) and fetal complications within the first month of post-natal life (ICU stay, sepsis, meconium aspiration, respiratory distress syndrome, grade 3-4 intraventricular hemorrhage, umbilical artery $\mathrm{pH}$ level and $5^{\text {th }}$ min Apgar score) were recorded. Patients were categorized into 2 groups on the basis of a 4-quadrant AFI $<5 \mathrm{~cm}(n=27)$ or $\geq 5 \mathrm{~cm}(n=21)$, while maternal and fetal characteristics and complications were evaluated with respect to AFI groups and correlation of AFI with other study parameters was analyzed.

\section{PPROM diagnosis}

PPROM diagnosis was based on patient history and physical examination findings including presence of typical gross amniotic fluid leakage history and/or identification of pooling of amniotic fluid in the posterior vaginal vault on sterile speculum examination. In women with suspected anamnesis but without history of gross leakage or positive findings on speculum examination, the diagnosis was made by positivity of placental alpha microglobulin-1 test (Amnisure ROM Test ${ }^{\circledR}$, QIAGEN, USA) in the vaginal fluid. The pregnant women were monitored daily by clinical and obstetric examination, as well as with bacteriology smears and periodic hemogram analysis for screening of infections.

\section{Calculation of amniotic fluid index (AFI)}

AFI was measured ultrasonographically with $4-8 \mathrm{MHz}$ transabdominal convex probe General Electric Voluson (GE Healthcare, Chicago, IL, United States) device and calculated by four quadrant technique, which is sum of the deepest vertical length of pocket of fluid in each quadrant without umbilical cord [17].

\section{Treatments}

All pregnant women received a single course of betamethasone, consisting of two 12-mg injections during the first 24 hours after admission to induce fetal lung maturation and antibiotic treatment including single dose oral azithromycin $(1 \mathrm{~g})$ and i.v. ampicillin $(4 \times 2 \mathrm{~g})$ within the first $48-\mathrm{h}$, as followed by oral amoxicillin $(3 \times 500 \mathrm{mg})$ to complete the 7-day antibiotherapy [1]. In women with delivery expected to occur before $32^{\text {nd }}$ gestational week, magnesium sulphate 
prophylaxis was administered for fetal neuroprotection (a loading dose of $6 \mathrm{~g}$ infused for 20-30 minutes followed by a maintenance infusion of $2 \mathrm{~g}$ per hour).

Emergency $\mathrm{C} / \mathrm{S}$ was performed in women with placental abruption and identification of decelerations indicating fetal distress during NST. The decelerations were interpreted in accordance with ACOG Bulletin description.

\section{Fetal and maternal complications}

Fetal and maternal complications were recorded up to 1 month postpartum. Respiratory distress syndrome was defined as a requirement for supplemental oxygen for more than 48 hours with a reticulogranular appearance on chest X-ray. Neonatal sepsis was diagnosed either by positive blood culture or by a combination of clinical signs and laboratory findings, such as leukopenia, thrombocytopenia, and elevated CRP levels. ICU need was considered for at least 24 hours of ICU stay in the neonatal period.

Chorioamnionitis was diagnosed based on increased body temperature $\left(>38^{\circ} \mathrm{C}\right)$ accompanied with positivity of at least one of the followings: lower abdominal or uterine tenderness, malodorous amniotic discharge, persistent fetal tachycardia or positive laboratory findings (CRP $>0.5 \mathrm{mg} / \mathrm{dL}$ or WBC > 20.000) [18]. Postpartum endometritis was diagnosed based on increased body temperature $\left(>38^{\circ} \mathrm{C}\right)$ and uterine tenderness and exclusion of other infection foci. Postpartum bleeding was considered in bleedings that cause $10 \%$ decline in hematocrit levels or necessitate blood transfusion.

\section{Statistical analysis}

Statistical analysis was made using IBM SPSS Statistics for Windows, version 25.0 (IBM Corp., Armonk, NY, USA). Pearson Chi-Square test (Exact), Fisher Exact test (Exact), Fisher Freeman Halton Test (Monte Carlo) were used to analyze categorical data, while numerical data were analyzed with independent samples-t test (Bootstrap) and Mann Whitney $\mathrm{U}$ test (Monte Carlo). Correlation analysis was performed with Spearman's rho test. ROC curve was plotted to determine the role of AFI in predicting fetal birth weight with calculation of area under curve (AUC) and cut-off value via ROC analysis. Data were expressed as median (min-max), 95\% confidence interval $(\mathrm{Cl})$ and $\mathrm{n}(\%)$ where appropriate $\mathrm{p}<0.05$ was considered statistically significant.

\section{RESULTS}

Overall, mean \pm SD maternal age was $27.15 \pm 5.04$ years, $54.2 \%$ of women were multiparous women. Mean PPROM time was 29.11 (SD 2.22) weeks, while spontaneous vaginal delivery was noted in $81.3 \%$ of women. Overall mean \pm SD AFI was $4.41 \pm 1.80 \mathrm{~cm}$, while AFI was $\leq 5 \mathrm{~cm}$ in 27 (56.3\%) patients and $>5 \mathrm{~cm}$ in 21 (43.7\%) patients. Median latency period was 8 days (range, 1 to 26 days), while length of postpartum LOS was 2.5 days (range, 1 to 7 days) (Tab. 1).

No significant difference was noted in maternal clinical and obstetric characteristics, gestational age at delivery and gender of the newborn with respect to AFI groups. Latency period and LOS were also similar between $\mathrm{AFI}<5 \mathrm{~cm}$ and $\geq 5 \mathrm{~cm}$ groups (Tab. 1 ).

Fetal birth weight was significantly higher in the $\mathrm{AFI} \geq 5 \mathrm{~cm}$ group as compared with $\mathrm{AFI}<5 \mathrm{~cm}$ group $(1622.86 \pm 273.75$ vs $1440.74 \pm 336.33, p=0.042)($ Tab. 1$)$.

\section{Maternal and fetal complications}

Overall, maternal complications were observed in $41.7 \%$ of women, including chorioamnionitis (33.3\%) and endometritis (25.0\%) in most of women (Tab. 2).

Overall, fetal complications were observed in $72.9 \%$ of neonates, including 5-min Apgar score $\leq 5$ (52.1\%), ICU stay $(66.7 \%)$, and respiratory distress syndrome $(52.1 \%)$ in most of neonates (Tab. 3).

No significant difference was noted in presence, type and number of maternal and fetal complications with respect to AFI groups (Tab. 3).

\section{Correlation of AFI with other study parameters}

AFI was correlated positively with latency period $(r=0.399, p=0.018)$ and negatively with postpartum LOS $(r=-0.314, p=0.030)$. No correlation of AFI was noted with maternal age, PPROM time, delivery week or number of maternal and fetal complications (Tab. 4).

\section{DISCUSSION}

Our findings revealed positive correlation of AFI with latency period and association of $\mathrm{AFI}<5 \mathrm{~cm}$ after PPROM with higher postpartum LOS in pregnancies complicated by PPROM at 23-33 weeks' gestation, whereas no significant difference was noted in fetal and maternal complication rates and mode of delivery with respect to AFI groups ( $<5 \mathrm{~cm}$ vs $\geq 5 \mathrm{~cm}$ ).

Increased likelihood of shorter latency to delivery with decreasing AFI values after PPROM in the current study supports the data on association of lower $(<5 \mathrm{~cm})$ AFI values with shorter latency to delivery reported from a prospective analysis of 225 singleton pregnancies complicated by PPROM between 24 and 32 weeks' gestation [12] as well as in a retrospective analysis of 389 women with PPROM between 24 and 34 weeks of gestation [14]. However, in both studies, authors also reported association of oligohydramnios after PPROM with higher rate of cesarean delivery $[12,14]$ and perinatal adverse outcomes such as early-onset neonatal sepsis [12] and chorioamnionitis [12,14]. In this regard, the wide range of latency period length (1-26 days) in the current study should also be noted given that this alone may also refer to a considerable risk factor of adverse outcome. 
Table 1. Maternal and fetal characteristics with respect to AF

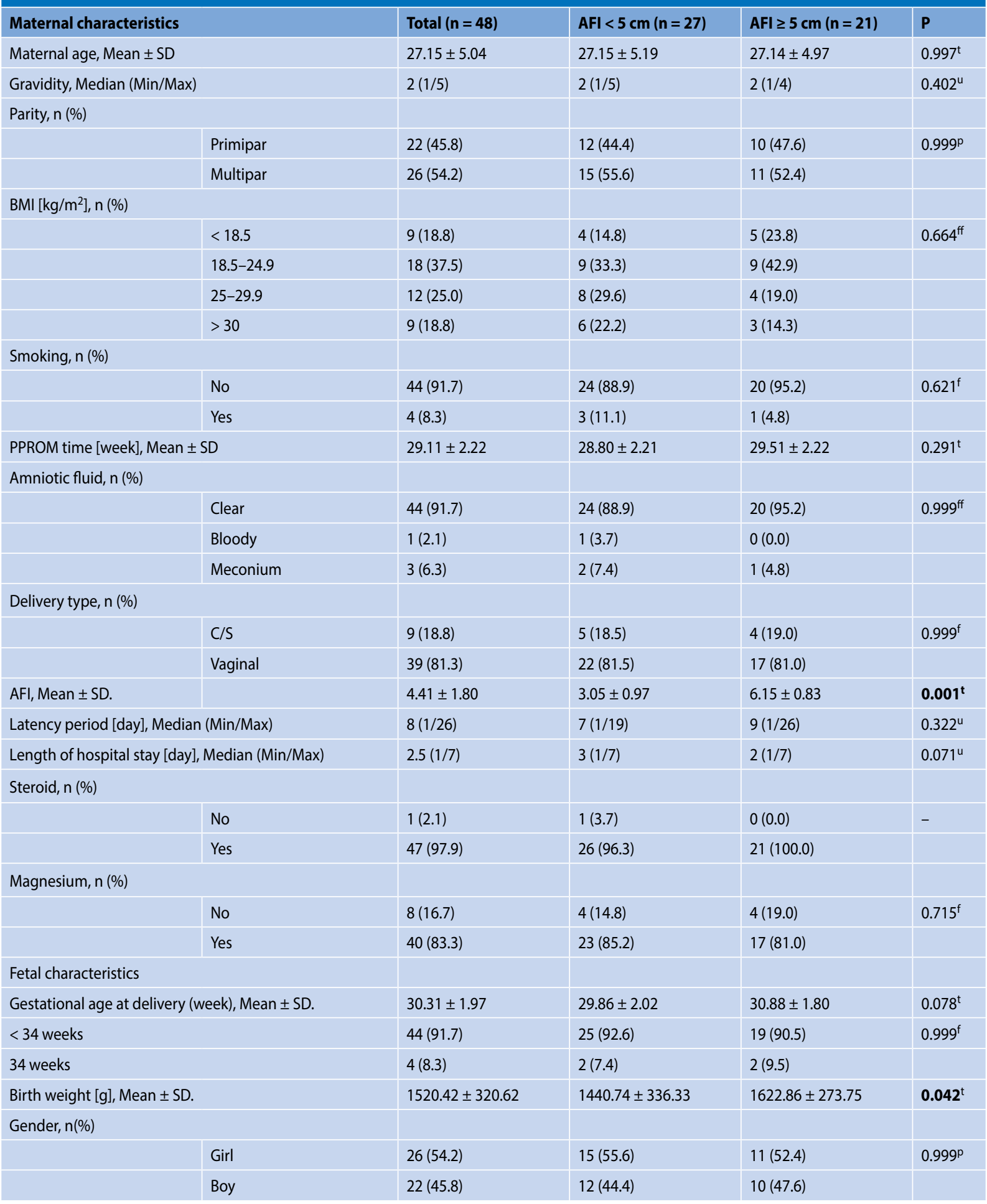

${ }^{\mathrm{t}}$ - Independent Samples, ${ }^{\mathrm{t}}$ - Test(Bootstrap), ${ }^{\mathrm{u}}$ - Mann Whitney U test(Monte Carlo), ${ }^{\mathrm{P}}$ - Pearson Chi-Square Test(Exact), ${ }^{\mathrm{f}}$ - Fisher Exact test(Exact), ${ }^{\mathrm{f}}$ - Fisher Freeman Halton Test(Monte Carlo), rc - Roc Curve Analysis (Youden index J-Honley\&Mc Nell), AUC - Area under the ROC curve, SD. - Standard deviation, Med - Median, Min - Minimum, Max — Maximum

In a retrospective study of 191 pregnancies with PPROM, authors reported higher rates of cesarean sections, 5-min Apgar score $<7$, chorioamnionitis, respiratory distress syndrome, composite neonatal morbidity and neonatal mortality in the group with an AFI $<5 \mathrm{~cm}$ vs those with an $\mathrm{AFI}>5 \mathrm{~cm}$ [19]. Moreover, in a retrospective cohort study of 86 pregnant women with PPROM at 24 to 35 weeks' gestation, authors reported higher rate of perinatal mortality in 


\begin{tabular}{|c|c|c|c|c|c|}
\hline & & Total $(n=48)$ & $A F I<5 \mathrm{~cm}(n=27)$ & $A F I \geq 5 \mathrm{~cm}(\mathrm{n}=21)$ & $\mathbf{P}$ \\
\hline & & Med (Min/Max) & Med (Min/Max) & Med (Min/Max) & \\
\hline \multirow[t]{2}{*}{ Number of complications } & & $0(0 / 3)$ & $0(0 / 3)$ & $0(0 / 3)$ & $0.349^{4}$ \\
\hline & & $\mathrm{n}(\%)$ & $\mathrm{n}(\%)$ & $\mathrm{n}(\%)$ & \\
\hline \multicolumn{6}{|l|}{ Complications } \\
\hline & Absent & $28(58.3)$ & $14(51.9)$ & $14(66.7)$ & $0.382^{p}$ \\
\hline & Present & $20(41.7)$ & $13(48.1)$ & $7(33.3)$ & \\
\hline \multicolumn{6}{|l|}{ Placental abruption } \\
\hline & Absent & 47 (97.9) & $26(96.3)$ & $21(100.0)$ & - \\
\hline & Present & $1(2.1)$ & $1(3.7)$ & $0(0.0)$ & \\
\hline \multicolumn{6}{|l|}{ Retention } \\
\hline & Absent & $46(95.8)$ & $26(96.3)$ & $20(95.2)$ & - \\
\hline & Present & $2(4.2)$ & $1(3.7)$ & $1(4.8)$ & \\
\hline \multicolumn{6}{|l|}{ Endometritis } \\
\hline & Absent & $36(75.0)$ & $19(70.4)$ & $17(81.0)$ & $0.510^{p}$ \\
\hline & Present & $12(25.0)$ & $8(29.6)$ & $4(19.0)$ & \\
\hline \multicolumn{6}{|l|}{ Bleeding } \\
\hline & Absent & $45(93.8)$ & $25(92.6)$ & $20(95.2)$ & $0.999^{f}$ \\
\hline & Present & $3(6.3)$ & $2(7.4)$ & $1(4.8)$ & \\
\hline \multicolumn{6}{|l|}{ Chorioamnionitis } \\
\hline & Absent & $32(66.7)$ & $17(63.0)$ & 15 (71.4) & $0.758^{p}$ \\
\hline & Present & $16(33.3)$ & $10(37.0)$ & $6(28.6)$ & \\
\hline \multicolumn{6}{|l|}{ CRP } \\
\hline & normal & $36(75.0)$ & $19(70.4)$ & $17(81.0)$ & $0.510^{p}$ \\
\hline & elevated & $12(25.0)$ & $8(29.6)$ & $4(19.0)$ & \\
\hline \multicolumn{6}{|l|}{ WBC } \\
\hline & $<21$ & $38(79.2)$ & $21(77.8)$ & $17(81.0)$ & $0.999^{f}$ \\
\hline & $>21$ & $10(20.8)$ & $6(22.2)$ & $4(19.0)$ & \\
\hline \multicolumn{6}{|l|}{ Body temperature $\left[{ }^{\circ} \mathrm{C}\right]$} \\
\hline & $<38$ & $32(66.7)$ & $17(63.0)$ & $15(71.4)$ & $0.758^{p}$ \\
\hline & $>38$ & $16(33.3)$ & $10(37.0)$ & $6(28.6)$ & \\
\hline
\end{tabular}

${ }^{\mathrm{u}}$ — Mann Whitney U test (Monte Carlo), ${ }^{\mathrm{p}}$ - Pearson Chi-Square Test (Exact), ${ }^{\mathrm{f}}$ — Fisher Exact test (Exact), Med — Median, Min — Minimum, Max — Maximum

$\mathrm{AFI}<5 \mathrm{~cm}$ vs $\mathrm{AFI}>5 \mathrm{~cm}$ groups, whereas a higher frequency of 1-min Apgar scores $<7$, neonatal sepsis and early neonatal mortality in $\mathrm{AFI}<3 \mathrm{~cm}$ vs $\mathrm{AFI}>3 \mathrm{~cm}$ groups [8].

Association of AFI scores $<5 \mathrm{~cm}$ with increased risk of chorioamnionitis and early onset neonatal sepsis [20,21] as well as an association of AFI scores with APGAR scores, neonatal respiratory distress syndrome and maternal chorioamnionitis [15] were also reported in other studies.

Besides, although oligohydramnios has been suggested as an important parameter in the evaluation of fetal wellbeing and a warning sign for predicting poor fetal prognosis in pregnancies complicated by PPROM $[8,12,14,15,18,19]$, there is no consensus on the optimal time to induce labor to enable a reduction of perinatal risks $[7,8]$.
Indeed, comparable to findings in our cohort, lack of association between AFI scores and adverse outcomes in pregnancies complicated by PPROM was also reported in other studies [5, 15]. In a past study of 161 singleton pregnancies complicated by PPROM, authors reported that AFI $<5 \mathrm{~cm}$ and $\mathrm{AFI} \geq 5 \mathrm{~cm}$ were similar in terms of gestational age at rupture of the membranes, gestational age at the delivery, mode of delivery, maternal chorioamnionitis, abruption, early onset neonatal sepsis and NICU stay as well as fetal birth weight [5]. No significant association of AFI with APGAR scores, neonatal RDS and maternal chorioamnionitis was also reported in another study [15].

Notably, in a retrospective cohort study in 92 women with PPROM, authors reported association of persistent 


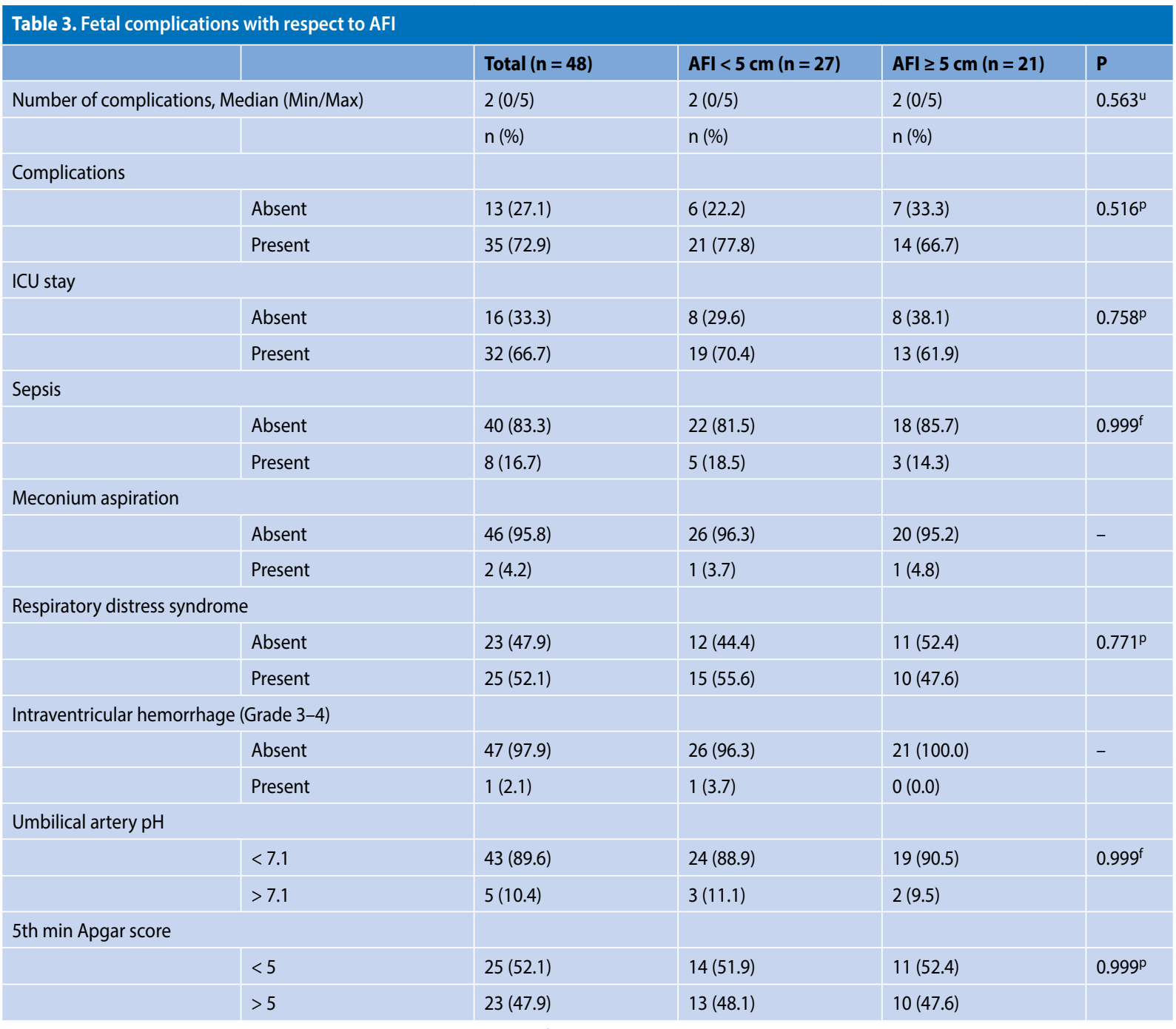

${ }^{\mathrm{u}}$ - Mann Whitney U test (Monte Carlo), ${ }^{\mathrm{p}}$ - Pearson Chi-Square Test (Exact), ${ }^{\mathrm{f}}$ - Fisher Exact test (Exact), Med — Median, Min — Minimum, Max — Maximum

\begin{tabular}{|l|l|l|}
\hline \multicolumn{3}{|l|}{ Table 4. Correlation of AFI with other study parameters } \\
\hline & AFI \\
\hline & r & P \\
\hline Age & 0.043 & 0.771 \\
\hline Gravidity & -0.118 & 0.425 \\
\hline BMI & -0.162 & 0.270 \\
\hline PPROM time & -0.120 & 0.417 \\
\hline Delivery week & 0.044 & 0.765 \\
\hline Birth weight & 0.146 & 0.321 \\
\hline Latency period (day) & 0.339 & $\mathbf{0 . 0 1 8}$ \\
\hline Post-partum length of hospital stay (day) & -0.314 & $\mathbf{0 . 0 3 0}$ \\
\hline Total number of maternal complications & -0.192 & 0.191 \\
\hline Total number of fetal complications & -0.0002 & 0.999 \\
\hline Spearman's rho test, $r$ - Correlation Coefficient & & \\
\hline
\end{tabular}

oligohydramnios with lower postnatal survival rate and more frequent developmental delay among neonates as compared with normal amniotic fluid volume, whereas they also indicated that most neonates born alive after PROM and persistent oligohydramnios to survive to discharge and to be developmentally normal [22]. Similarly, while prolonged oligohydramnios following PPROM has traditionally been associated with poor fetal outcomes including high neonatal mortality, an apparent improvement in outcome has also been emphasized recently even amongst the highest risk infants with documented persistent oligohydramnios [16].

Hence, the controversy regarding the association of oligohydramnios with adverse maternal and neonatal outcome in PPROM in published studies seems to emphasize the need for this association to be investigated by further larger scale studies with sufficient number of patients with low AFI [5, 12, 20, 23].

Although, higher fetal birth weight in the AFI $\geq 5 \mathrm{~cm}$ group as compared with $\mathrm{AFI}<5 \mathrm{~cm}$ group in our cohort seems consistent with previously reported role of $\mathrm{AFI}$ in predicting macrosomia in a prospective observational study 
in 600 patients in the first stage of labor before rupture of membranes [24], it should be noted that latency period and the mean gestational age at the delivery also differed between AFI groups emphasizing the birthweight to be variable dependent on gestational age and placental factors rather than on residual AFI.

In fact, while oligohydramnios has been associated with a higher likelihood of caesarean section due to non-reassuring fetal heart rate patterns $[5,12,20]$ as well as with longer NICU stay [25], our findings revealed similar cesarean section delivery rates and length of NICU stay in AFI $\geq 5 \mathrm{~cm}$ and $<5 \mathrm{~cm}$ groups. Nevertheless, caesarean section rate $(18.8 \%)$ in our cohort of women with pregnancies complicated by PPROM at 23-33 weeks' gestation seems in accordance with the likelihood of an increased risk of maternal infection in cesarean sections, particularly in women at risk of developing chorioamnionitis [23, 26].

\section{CONCLUSIONS}

In conclusion, our findings seem to indicate increased likelihood of shorter latency to delivery and longer postpartum LOS with decrease in AFI after PPROM between 23-33 weeks' gestation, whereas no impact of AFI on mode of delivery and fetal or maternal complications. Further larger scale longitudinal studies in pregnant women with PPROM are needed to investigate the utility of AFI as a potential prognostic variable in predicting adverse fetal or maternal outcomes.

\section{Conflict of interest}

The authors declare that they have no conflict of interest.

\section{Ethical approval}

Written informed consent was obtained from each subject following a detailed explanation of the objectives and protocol of the study which was conducted in accordance with the ethical principles stated in the "Declaration of Helsinki" and approved by the institutional ethics committee.

\section{Informed consent}

Written informed consent was obtained from each subject following a detailed explanation of the objectives and protocol of the study.

\section{REFERENCES}

1. American College of Obstetricians and Gynecologists (2013) Premature rupture of membranes. Practice Bulletin No. 139. Obstet Gynecol 122:918-930. https://doi.org/10.1097/01.AOG.0000435415.21944.8f

2. Mercer BM (2003) Preterm premature rupture of the membranes. Obstet Gynecol 101:178-193. https://doi.org/10.1016/s0029-7844(02)02366-9

3. Dartibale CB, Uchimura NS, Nery L, Schumeish AP, Uchimura LYT, Santana RG, Uchimura TT (2017) Qualitative Determination of Human Chorionic Gonadotropin in Vaginal Washings for the Early Diagnosis of Premature Rupture of Fetal Membranes. Rev Bras Ginecol Obstet 39:317-321. https://doi.org/10.1055/s-0037-1603939
4. Tigga M, Malik S (2014) Various biomarkers in diagnosing premature rupture of membranes: a cost effective analysis. Internet J Gynecol Obstet 19:1-6. https://doi.org/10.5580/IJGO.20709

5. Saraswathy A, Vaman JV, Brahmanandan M, Nirmala C (2018) Correlation between obstetric outcome and amniotic fluid index (AFI) in preterm prelabour rupture of membranes (PPROM). Int J Reprod Contracept Obstet Gynecol 7:4858-4861. http://dx.doi.org/10.18203/2320-1770. ijrcog20184929

6. Caughey AB, Robinson JN, Norwitz ER (2008) Contemporary diagnosis and management of preterm premature rupture of membranes. Rev Obstet Gynecol 1:11-22.

7. Nabhan AF, Abdelmoula YA (2008) Amniotic fluid index versus single deepest vertical pocket as a screening test for preventing adverse pregnancy outcome. Cochrane Database Syst Rev (3):CD006593. https:// doi.org/10.1002/14651858.CD006593.pub2

8. Souza AS, Patriota AF, Guerra GV, Melo BC (2016) Evaluation of perinatal outcomes in pregnant women with preterm premature rupture of membranes. Rev Assoc Med Bras (1992) 62:269-275. https://doi. org/10.1590/1806-9282.62.03.269

9. Tavassoli F, Ghasemi M, Mohamadzade A, Sharifian J (2010) Survey of pregnancy outcome in preterm premature rupture of membranes with amniotic fluid index $<5$ and $\geq 5$. Oman Med J 25:118-123. https://doi. org/10.5001/omj.2010.32

10. Melamed N, Ben-Haroush A, Pardo J, Chen R, Hadar E, Hod M, Yogev Y (2011) Expectant management of preterm premature rupture of membranes: is it all about gestational age? Am J Obstet Gynecol 204:48.e1-8. https://doi.org/10.1016/j. ajog.2010.08.021

11. Vintzileos AM, Campbell WA, Nochimson DJ, Weinbaum PJ (1985) Degree of oligohydramnios and pregnancy outcome in patients with premature rupture of the membranes. Obstet Gynecol 66:162-167.

12. Vermillion ST, Kooba AM, Soper DE (2000) Amniotic fluid index values after preterm premature rupture of the membranes and subsequent perinatal infection. Am J Obstet Gynecol 183:271-276. https://doi. org/10.1067/mob.2000.107653

13. Frenette P, Dodds L, Armson BA, Jangaard K (2013) Preterm prelabour rupture of membranes: effect of latency on neonatal and maternal outcomes. J Obstet Gynaecol Can 35:710-717. https://doi. org/10.1016/S1701-2163(15)30861-6

14. Ekin A, Gezer C, Taner CE, Ozeren M (2015) Perinatal outcomes in pregnancies with oligohydramnios after preterm premature rupture of membranes. J Matern Fetal Neonatal Med 28:1918-1922. https://doi.org /10.3109/14767058.2014.972927

15. Piazze J, Anceschi MM, Cerekja A, Brunelli R, Meloni P, Marzano S, Cosmi E (2007) Validity of amniotic fluid index in preterm rupture of membranes. J Perinat Med 35:394-398. https://doi.org/10.1515/JPM.2007.077

16. Williams O, Hutchings $G$, Debieve F, Debauche $C$ (2009) Contemporary neonatal outcome following rupture of membranes prior to 25 weeks with prolonged oligohydramnios. Early Hum Dev 85:273-277. https:// doi.org/10.1016/j.earlhumdev.2008.11.003

17. Magann EF, Sanderson M, Martin JN, Chauhan S (2000) The amniotic fluid index, single deepest pocket, and two-diameter pocket in normal human pregnancy. Am J Obstet Gynecol 182:1581-1588. https://doi. org/10.1067/mob.2000.107325

18. Kim CJ, Romero R, Chaemsaithong P, Chaiyasit N, Yoon BH, Kim YM (2015) Acute chorioamnionitis and funisitis: definition, pathologic features, and clinical significance. Am J Obstet Gynecol 213:S29-52. https://doi. org/10.1016/j.ajog.2015.08.040

19. Kurdoglu M, Kolusari A, Adali E, Yildizhan R, Kurdoglu Z, Kucukaydin Z, Kaya A, Kirimi E, Sahin HG, Kamaci M (2010) Does residual amniotic fluid after preterm premature rupture of membranes have an effect on perinatal outcomes? 12 years' experience of a tertiary care center. Arch Gynecol Obstet 281:601-607. https://doi.org/10.1007/s00404-009-1147-4

20. Borna S, Borna H, Khazardoost S, Hantoushzadeh S (2004) 'Perinatal outcome in preterm premature rupture of membranes with Amniotic fluid index< 5 (AFI< 5). BMC Pregnancy Childbirth 4:15. https://doi. org/10.1186/1471-2393-4-15

21. Mousavi AS, Hashemi N, Kashanian M, Sheikhansari N, Bordbar A, Parashi $S$ (2018) Comparison between maternal and neonatal outcome of PPROM in the cases of amniotic fluid index (AFI) of more and less than $5 \mathrm{~cm}$. J Obstet Gynaecol 38:611-615. https://doi.org/10.1080/01 443615.2017.1394280

22. Lee JY1, Ahn TG, Jun JK (2015) Short-Term and Long-Term Postnatal Outcomes of Expectant Management After Previable Preterm Premature Rupture of Membranes With and Without Persistent Oligohydramnios. Obstet Gynecol 126:947-953. https://doi.org/10.1097/AOG.0000000000001099 
23. Huang S, Qi HB, Li L (2009) Residue amniotic fluid volume after preterm premature rupture of membranes and maternal-fetal outcome. Zhonghua Fu Chan Ke Za Zhi 44:726-730.

24. El Khouly NI, Elkelani OA, Saleh SA (2017) Amniotic fluid index and estimated fetal weight for prediction of fetal macrosomia: a prospective observational study. J Matern Fetal Neonatal Med 30:1948-1952. https:// doi.org/10.1080/14767058.2016.1233398
25. Ladella S, Leung T, Cortez C (2017) Effects of Amniotic Fluid Index on Perinatal Outcomes in Preterm Premature Rupture of Membranes [370]. Obstet Gynecol 129:S162. https://doi.org/10.1097/01.AOG.0000514786.52391.ba

26. Fernandes GL, Torloni MR, Hisaba WJ, Klimke D, Novaes J, Sancovski M, Peixoto S (2012) Premature rupture of membranes before 28 weeks managed expectantly: maternal and perinatal outcomes in a developing country. JObstet Gynaecol 32 :45-49. https://doi.org/10.3109/01443615.2011.609923 